\title{
COORDINATING ACTIVITIES OF THE PROSECUTOR'S OFFICE TO COUNTERACT AND PREVENT EXTREMISM AMONG MIGRANT WORKERS IN MODERN RUSSIA
}

\author{
Davlatali G. Kakhkhorov \\ Volgograd State University, Volgograd, Russian Federation \\ Vagip M. Abdrashitov \\ Volgograd State University, Volgograd, Russian Federation \\ Shavkat H. Machidzoda \\ Kanibadam Prosecutor's Office, Kanibadam, Republic of Tajikistan
}

\begin{abstract}
Introduction: at the present stage of state and law development, the formation of interstate relations of a new format takes place in the context of rather complex and contradictory processes, whose many participants, demonstrating different levels of resistance, become vulnerable to both traditional and new challenges and threats of modern history. One of these threats is extremist activity, which is a real threat to the constitutional order and national security of any state. In recent decades, such phenomena as xenophobia, separatism, religious fanaticism and terrorism, various nationalist sentiments that develop into an active movement and extremism of various etiologies have been actively developed. For Russia, as a multi-ethnic democratic state, these phenomena are particularly dangerous, since they undermine the peaceful coexistence of various ethnic and social groups. In addition, the development of information technologies makes it more accessible to carry out extremist activities among the general population. The social networks are increasingly used by the supporters of terrorism and extremism to conduct active propaganda and vigorous recruitment. In this regard, the authors of the paper set a goal to study the real state of the prosecutor's supervision over the implementation of laws on countering extremism among migrant workers, as well as to develop new forms of coordinating activities of the prosecutor's office to prevent and suppress acts of extremist activity in the context of modern political and economic challenges of the modern Russian state and the world as a whole. Methods: the methodological framework for this research is a set of methods of scientific knowledge, among which the main ones are the methods of synthesis, scientific generalization and comparative law analysis. Results: despite giving the Prosecutor General's Office the power to block the sites containing extremist information and remove direct calls for extremist activity, the issue of combating this phenomenon remains particularly topical. In this regard, the importance of coordinating, organizing and implementing the effective control over countering extremist activities, and improving the activities of the law enforcement agencies headed by the Prosecutor General's Office of the Russian Federation in the fight against extremism is increasing in every possible way. Conclusions: only joint, well-thought-out and well-coordinated activities, led by the Prosecutor General's Office of the Russian Federation, will prevent the main threats and minimize the negative impact of extremist activities on all sides, aspects and areas of functional activity of the modern Russian state, which is thus fighting not only extremism in all its manifestations, but also related phenomena, including nationalism, chauvinism, separatism, xenophobia, religious and mono-ethnic fanaticism and terrorism, as the most dangerous form of extremism.
\end{abstract}

Key words: prosecutor, prosecutor's office, coordinating activities, extremism, types of extremism, fight against extremism, forms of coordinating activities. 


\title{
КООРДИНАЦИОННАЯ ДЕЯТЕЛЬНОСТЬ ОРГАНОВ ПРОКУРАТУРЫ ПО ПРОТИВОДЕЙСТВИЮ И ПРОФИЛАКТИКЕ ЭКСТРЕМИЗМА СРЕДИ ТРУДОВЫХ МИГРАНТОВ В СОВРЕМЕННОЙ РОССИИ
}

\author{
Давлатали Гаффорович Каххоров \\ Волгоградский государственный университет, г. Волгоград, Российская Федерация \\ Вагип Мнирович Абдрашитов \\ Волгоградский государственный университет, г. Волгоград, Российская Федерация \\ Шавкат Хабибулло Мачидзода \\ Прокуратура города Канибадама, г. Канибадам, Республика Таджикистан
}

\begin{abstract}
Введение: на современном этапе развития государства и права формирование межгосударственных отношений нового формата протекает в условиях достаточно сложных и противоречивых процессов, многие участники которых, демонстрируя разный уровень резистентности, становятся уязвимыми перед лицом как традиционных, так и новых вызовов и угроз новейшей истории. Одной из них является экстремистская деятельность, представляющая собой реальную угрозу конституционному строю и национальной безопасности любого государства. В последние десятилетия активное развитие получили такие явления, как ксенофобия, сепаратизм, религиозный фанатизм и терроризм, различные националистические настроения, перерастающие в деятельное движение и экстремизм различной этиологии. Для России как многонационального демократического государства эти явления особенно опасны, поскольку подрывают мирное сосуществование различных этнических и социальных групп. Кроме того, развитие информационных технологий делает более доступным осуществление экстремисткой деятельности среди широких слоев населения. Социальные сети все чаще используются сторонниками терроризма и экстремизма для ведения активной пропаганды и энергичного рекрутинга. В связи с этим авторами статьи была поставлена цель изучить реальное состояние прокурорского надзора за исполнением законов о противодействии экстремизму среди трудовых мигрантов, а также разработать новые формы координационной деятельности органов прокуратуры по предупреждению и пресечению актов экстремистской деятельности в условиях современных политических и экономических вызовов современного российского государства и мира в целом. Методы: методологическую основу данного исследования составляет совокупность методов научного познания, среди которых основное место занимают синтез, научное обобщение и сравнительно-правовой анализ. Результаты: несмотря на наделение Генпрокуратуры полномочиями по блокировке сайтов, содержащих информацию экстремистского характера, удалению прямых призывов к экстремистской деятельности, вопрос борьбы с подобным явлением остается особенно актуальным. В связи с этим повсеместно возрастает необходимость координации, организации и осуществления эффективного контроля в сфере противодействия экстремистской деятельности, совершенствования деятельности правоохранительных органов во главе с Генеральной Прокуратурой Российской Федерации при осуществлении борьбы с экстремизмом. Выводы: только совместная, глубоко продуманная и качественно скоординированная деятельность, возглавляемая Генеральной Прокуратурой Российской Федерации, позволит предотвратить основные угрозы и минимизировать негативное влияние экстремистской деятельности на все стороны, аспекты и направления функциональной деятельности современного российского государства, борющегося тем самым не только с экстремизмом во всех его проявлениях, но и со смежными и родственными явлениями, включая национализм, шовинизм, сепаратизм, ксенофобию, религиозный и моноэтнический фанатизм и терроризм как наиболее опасные формы экстремизма.

Ключевые слова: прокурор, прокуратура, координационная деятельность, экстремизм, виды экстремизма, борьба с экстремизмом, формы координационной деятельности.
\end{abstract}

Цитирование. Каххоров Д. Г., Абдрашитов В. М., Мачидзода Ш. Х. Координационная деятельность органов прокуратуры по противодействию и профилактике экстремизма среди трудовых мигрантов в современной России // Legal Concept = Правовая парадигма. -2020 . - T. 19, № 2. - C. 27-34. - DOI: https://doi.org/10.15688/ lc.jvolsu.2020.2.4 


\section{Введение}

Стремительное развитие информационных технологий послужило возникновению нового вида правонарушений - размещение материалов экстремистского характера в сети Интернет. Именно они обеспечивают донесение идей розни, ненависти, злобы и вражды до широкого круга общественности. Постоянное обновление повестки дня, актуализация международных стандартов в области защиты прав и свобод человека [6] при постепенном понижении морально-этических требований и культурных норм, популяризация и повышение порога насилия путем совершения все более зрелищных, бесчеловечных и жестоких действий ведут к тому, что глобализация мирового информационного пространства постепенно расширяет границы психологического воздействия злоумышленников до международного уровня.

В связи с этим деятельность прокуратуры Российской Федерации в сфере надзора за исполнением антиэкстремистского законодательства приобретает сложный по своей структуре и содержанию характер. Это объясняется тем, что на органы прокуратуры России возложены широкие полномочия по обеспечению законности во многих сферах правоотношений, и чем более они сложны по своим сути и структуре, тем больше существенных особенностей приобретает надзорная деятельность.

Согласно статистическим данным Генпрокуратуры РФ, наибольший удельный вес среди преступлений террористического и экстремистского характера принадлежит Центральному, Приволжскому и Северо-Кавказскому федеральным округам. Большая часть преступных действий выявляется в ходе проведения проверок традиционных объектов террористического посягательства - объектов промышленности, транспорта, связи, военных объектов, жилых и административных зданий, мест постоянного нахождения людей и др. Профилактика антитеррористической деятельности достигается также благодаря проводимому органами прокуратуры надзору за исполнением законов при установлении источников распрост- ранения террористической информации и литературы, а также каналов вербовки в экстремистские группировки и каналы их финансирования.

Стремительное развитие информационных технологий позволяет сторонникам экстремизма активно использовать глобальную сеть Интернет, социальные сети для распространения информации экстремистского характера и вовлекать молодежь в экстремистские и террористические организации [1, с. 117-118]. В качестве мер прокурорского реагирования по противодействию распространения этой преступной идеологии в 2016 г. Генеральной прокуратурой РФ направлены в Роскомнадзор более 400 требований о блокировке интернетсайтов, содержащих информацию экстремистского характера (заблокировано более 1800 интернет-ресурсов, из них 450 сайтов, созданных для финансирования боевиков в Сирии) [9], удалении информации террористического содержания (с 17000 сайтов удалена информация с призывами к терроризму и экстремистской деятельности). В ряде субъектов РФ организовано межведомственное взаимодействие органов прокуратуры и территориальных управлений Роскомнадзора по средствам электронных каналов связи.

Например, по инициативе прокуратуры Республики Татарстан создана специальная программа «Система противодействия правонарушениям в Интернете I.C.М.», которая осуществляет мониторинг интернет-ресурсов в режиме онлайн и автоматически распознает запрещенный контент. В случае его обнаружения программа уведомляет Роскомнадзор о целесообразности блокировки такого сайта, а в отдельных случаях формирует необходимый перечень документов для обращения в судебные органы [3], в отношении как россиян, так и иностранных граждан, осуществляющих деятельность экстремистской направленности. Особой мерой прокурорского реагирования в сфере борьбы с экстремистской деятельностью является возможность органов прокуратуры обращаться в судебные органы с требованиями о признании информационных материалов экстремистскими. 


\section{Особенности надзорной деятельности прокуратуры по профилактике и противодействию экстремизму среди трудовых мигрантов}

В целях обеспечения национальной безопасности и предотвращения криминальных действий экстремистов ежегодно законодательными органами России принимаются десятки нормативно-правовых актов, также вносятся многочисленные изменения в уже существующие. С одной стороны, принятие такого количества нормативно-правовых актов расширяет круг полномочий должностных лиц правоохранительных органов по борьбе с экстремизмом, а с другой - возлагает на них дополнительную ответственность за сохранение мира и безопасности в российском обществе.

С изданием Указа Президента Российской Федерации от 23.03.1995 № 310 «О мерах по обеспечению согласованных действий органов государственной власти в борьбе с проявлениями фашизма и иных форм политического экстремизма в Российской Федерации» прошло двадцать пять лет. За эти годи выявление, предупреждение и пресечение экстремистской деятельности общественных и религиозных объединений, а также иных организаций и физических лиц остается одним из важных и приоритетных направлений надзорной деятельности органов прокуратуры.

О важности направлений надзорной деятельности прокуратуры в борьбе с экстремизмом также свидетельствует ряд факторов.

Во-первых, надзорная деятельность прокурора по борьбе с экстремизмом регламентируется не только Федеральным законом «О прокуратуре Российской Федерации» от 17.01.1992 г. № 2202-1, но и другими специализированными федеральными законами. В частности, согласно ст. 6, 7 и 8 Федерального закона «О противодействии экстремисткой деятельности» от 25.07.2002 г. №114-Ф3, Генеральный прокурор или его заместитель либо подчиненный ему соответствующий прокурор или его заместитель в целях предотвращения или недопустимости противоправных действий, содержащих признаки экстремисткой деятельности, выносит в письменной форме предостережение и предупреждение. Кро- ме того, на основании заявления Генерального прокурора РФ или подчиненного ему прокурора (ст. 9) суд принимает решение о признании деятельности общественного или религиозного объединения экстремистской организацией. За период 2003-2015 гг. по инициативе прокуратуры судами приняты вступившие в законную силу решения о признании 46 организаций экстремистскими. В частности, «Правый сектор», «Братство», «ИГИЛ», «Джибхат Ан-Нусра» и др. [5, с. 43]. Следует отметить, что не только Россия борется с различными проявлениями экстремизма. Подобная деятельность ведется и в других государствах-членах СНГ.

Так, с 2006 по 2016 г. Верховный суд Республики Таджикистан на основе заявлений Генерального прокурора Республики Таджикистан принял многочисленные постановления о признании экстремистской деятельность некоторых организаций и партий, действующих на территории государства и за ее пределами, в числе которых оказались: «Аль-Каида», «Исламское движение Восточный Туркестан», «Исламская партия Туркестан», «Исламское движение Талибан», «Исламское движение Узбекистан», «Хизб-ут-Тахрир», «Братья-мусульмане», «Лашкаре-Тайба», «Джамаат Таблиг», «Исламское общество пропаганда», «Свободный Таджикистан», «Салафия», «ПИВТ», «Исламское государство» и т. д. [4, с. 31].

Во-вторых, в структуре аппарата Генеральной прокуратуры Российской Федерации действует Управление по надзору за исполнением законов о федеральной безопасности, межнациональных отношениях, противодействии экстремизму и терроризму. Деятельность данного управления регулируется Положением об управлении по надзору за исполнением законов о федеральной безопасности, межнациональных отношениях, противодействии экстремизму и терроризму [7].

Структура надзорной деятельности органов прокуратуры в сфере профилактики экстремизма имеет три уровня: первый - организационный. Это общий уровень прокурорского надзора за соблюдением антиэкстремистского законодательства в целом. Второй уровень касается надзорной деятельности за исполнением антиэкстремистского законодательства при расследовании преступ- 
лений определенного вида. Третий уровень индивидуальный, включает в себя организацию прокурорского надзора за исполнением антиэкстремистского законодательства при расследовании конкретного преступления.

Особое внимание необходимо обратить на тот факт, что надзорная деятельность органов прокуратуры в сфере борьбы с экстремизмом представляет собой последовательность определенных циклов, которые образуют единый цикл, целью которого является обеспечение законности на этапе предварительного расследования. Наличие отдельных циклов, в свою очередь, объясняется существованием различных стадий предварительного расследования, на каждой из которых решаются самостоятельные задачи. Взаимосвязь данных стадий обусловлена тем, что решение задач предыдущего этапа является основанием для перехода к следующему. Последовательность стадий позволяет рассматривать предварительное расследование как единую, последовательно развивающуюся процессуальную деятельность.

Специалистами прокуратуры отмечено, что основным объектом вербовочной деятельности становятся молодые люди 2025 лет как наиболее активные пользователи социальных сетей и различных интернет-форумов. Способы вербовки самые различные: от простого сонника или гаданий в интернете до игр в кабельных сетях. Как правило, наиболее предрасположены к воздействию злоумышленников три категории граждан: студенты, мигранты и заключенные.

Важным направлением деятельности является надзор за соблюдением миграционного законодательства, нарушения которого приводят к возникновению конфликтов на национальной почве, что неизбежно ведет к появлению идей превосходства одной этнической или религиозной группы над другой и последующему разжиганию вражды между ними. Особенно опасно проникновение в государство мигрантов - представителей разного рода экстремистских и террористических организаций. Другим важным направлением остается координация деятельности правоохранительных органов по выявлению и пресечению участия в массовых мероприятиях лиц, склонных к экстремистской деятельности.
Трудовые мигранты (особенно из Центральной Азии), прибывающие в Россию в целях заработка, находятся в другой культурной и языковой среде, живут в условиях постоянного психологического стресса, в связи с чем вербовщики легко устанавливают в их среде тех, кто разделяет экстремистские взгляды, и после незначительной предварительной проработки предлагают этим людям деньги за участие сначала в разовых акциях протеста, стачках, забастовках, «маршах несогласных», а далее - в боевых действиях. Так, активному распространению идеологии экстремизма среди мигрантов способствует пропаганда превосходства норм шариата перед действующим национальным законодательством и превращение территории конкретного субъекта российского государства в очередную провинцию «Всемирного халифата». В качестве одной из основных контрмер по указанной области деятельности надзор за исполнением законов о миграции, осуществляемый органами прокуратуры, стал рассматриваться в виде одного из приоритетных направлений прокурорской деятельности. Теперь особое внимание уделяется деятельности должностных лиц органов, контролирующих соблюдение миграционного законодательства, а также работодателей, использующих труд мигрантов.

Согласно статистическим данным большая часть нарушений связана с ненадлежащим исполнением уполномоченными органами требований миграционного законодательства в сфере контроля за въездом, пребыванием и выездом иностранных лиц (только в 2016 г. в этой сфере выявлено около 40000 нарушений) [8].

Наиболее часто нарушения связаны с содержанием иностранных граждан в центрах временного пребывания (например, превышение нормативной вместимости), а также исполнением административного наказания в виде выдворения мигрантов за пределы страны. Так, администрации некоторых центров отказывались принимать мигрантов, несмотря на решения судов об административном выдворении. Из-за недостатка финансирования некоторые иностранцы были вынуждены ожидать депортации длительное время. При этом месячное содержание только одного мигранта обходится бюджету государства больше стоимости авиабилета из России в 
любую из стран ближнего зарубежья более чем в два раза.

Одним из условий существования экстремистских и террористических организаций является их финансирование. Значительные силы направлены именно на ликвидацию каналов и источников финансирования и ресурсной подпитки экстремизма и терроризма [2, c. 224-225], в том числе по пресечению афганского наркотрафика, за счет которого (по данным Группы СБ ООН по мониторингу АльКаиды и движения Талибан) одна треть общего бюджета Талибана формируется от наркоторговли.

Как показывает практика прокурорского надзора, не всегда органами предварительного расследования принимаются исчерпывающие меры по выявлению и пресечению каналов финансирования, недостаточно используются возможности Росфинмониторинга по блокировке счетов субъектов криминальной деятельности.

Взаимодействие органов прокуратуры с такими структурами, как Минюст РФ, ФСБ РФ, МВД России, позволило предотвратить в период 2016-2019 гг. вмешательство во внутреннюю политику РФ восьми организаций, которые были признаны экстремистскими, одна их них - террористической, причем все они имели иностранные центры управления.

Большие трудности по выявлению каналов финансирования создают набирающие популярность криптовалюты, которые позволяют осуществлять взаимодействие отправителя и получателя качественно иным образом. Особенности шифрования криптовалют позволяют достичь высокой степени анонимности участников финансовых операций, в результате чего такой инновационный характер нивелирует все имеющиеся меры борьбы с финансированием экстремистских организаций. Сложившаяся ситуация требует внесения соответствующих изменений в международное и национальное уголовное законодательство. Учитывая отсутствие в настоящее время какого-либо правового регулирования криптовалют на национальном уровне, представляется целесообразной унификация международного и национального законодательства, регламентирующего сферу платежных сервисов, электронных платежных систем и виртуальных валют.

\section{Заключение}

Таким образом, органам прокуратуры необходимо шире и более активно использовать весь арсенал имеющихся полномочий, предоставленных действующим национальным законодательством России. Необходим системный и методичный подход при осуществлении надзора за исполнением антиэкстремистского и антитеррористического законодательства всеми органами, имеющими компетенции и схожие полномочия в указанной сфере. К большому сожалению, стоит признать, что только активная деятельность прокуратуры часто является единственно возможной мерой воздействия на эти органы, которая бы понуждала их к наиболее эффективному и последовательному осуществлению своих полномочий, исполнению возложенных на них обязанностей по борьбе с нарушениями экстремистского характера, а требования прокуроров, адресованные руководителям общественных и религиозных организаций, нередко служат достаточным поводом и исключительным основанием к пересмотру административных, организационных, финансовых решений и нормативных предписаний. К указанному стоит добавить, что существенному укреплению режима законности в исследуемой области будет способствовать рациональное обновление и систематизация антиэкстремистского и антитеррористического законодательства, совершенствование правоприменительной практики в части регулирования актов прокурорского надзора, разумное использование международного и европейского опыта борьбы с незаконной миграцией и терроризмом [10, с. 4623-4624], а также разумное внедрение эффективных зарубежных экспериментов в области миграционного законодательства отдельных стран.

\section{СПИСОК ЛИТЕРАТУРЫ}

1. Абдрашитов, В. М. Применять ли презумпцию невиновности в борьбе с коррупцией и терроризмом? / В. М. Абдрашитов // Российский криминологический взгляд. - 2007. - № 4. - С. 117-119.

2. Елисеев, А. М. Феномен ИГИЛ: пути решения проблемы / А. М. Елисеев, А. М. Абдрашитов // Теоретические и практические аспекты раз- 
вития научной мысли в современном мире : сб. ст. междунар. науч.-практ. конф. / отв. ред. А. А. Сукиасян. - Екатеринбург : [б. и .], 2015. -С. 224-225.

3. Информационное письмо Генеральной прокуратуры РФ от 10.10.2016 № 27-29-2016/Ип10378-16 «Об особенностях надзорной деятельности по пресечению распространения материалов экстремистского характера в сети “Интернет” в первом полугодии 2016 г.». - Доступ из справ.-правовой системы «КонсультантПлюс».

4. Каххоров, Д. Г. Современные проблемы борьбы с религиозным экстремизмом на постсоветском пространстве (на примере Республики Таджикистан) / Д. Г. Каххоров // Проблемы противодействия преступлениям экстремистской направленности на современном этапе развития России : материалы регионального круглого стола (г. Волгоград, 31 мая 2019 г.) / под ред. В. Н. Троневой. Волгоград : Изд-во Волгоградского института управления - филиала РАНХиГС, 2019. - С. 28-33.

5. Меркурьев, В. М. Задачи прокуратуры Российской Федерации по противодействию экстремизму и терроризму в контексте обеспечения национальной безопасности / В. М. Меркурьев // Вестник Академии Генеральной прокуратуры Российской Федерации. - 2016. - № 3 (53). - С. 44-53.

6. Послание Президента Российской Федерации Федеральному Собранию от 15.01.2020. Доступ из справ.-правовой системы «КонсультантПлюс».

7. Приказ Генерального прокурора Российской Федерации от 10.11.2017 г. «Положение об управлении по надзору за исполнением законов о федеральной безопасности, межнациональных отношениях, противодействии экстремизму и терроризму». - Электрон. текстовые дан. - Режим доступа: https://genproc.gov.ru/documents/orders/document14312 (дата обращения: 22.02.2020). - Загл. с экрана.

8. Сводный отчет Генеральной прокуратуры РФ по форме ОН за январь - декабрь 2016 г. «Надзор за исполнением законов, соблюдением прав и свобод человека и гражданина». - Электрон. текстовые дан. - Режим доступа: https://genproc.gov.ru/anticor/ doks (дата обращения: 22.02.2020). - Загл. с экрана.

9. Справка о состоянии законности в сфере межнациональных отношений и противодействии экстремистской деятельности в 2016 г. Генеральной прокуратуры РФ. - Электрон. текстовые дан. - Режим доступа: https:/genproc.gov.ru/stat/data/?PAGEN_1=3 (дата обращения: 22.02.2020). - Загл. с экрана.

10. Davletgildeev, R. Sh. Organization for Security and Cooperation in Europe: Analysis of State, Prospects and Opportunities for Cooperation Against the Illegal Migration and Terrorism / R. Sh. Davletgildeev, S. A. Kostin // HELIX. - 2018. - Vol. 8, iss. 6. P. 4623-4624.

\section{REFERENCES}

1. Abdrashitov V.M. Primenyat li prezumpciyu nevinovnosti $\mathrm{v}$ borbe $\mathrm{s}$ korruptsiey i terrorizmom? [Should the Presumption of Innocence be Applied in the Fight Against Corruption and Terrorism?]. Rossiyskiy kriminologicheskiy vzglyad [Russian Criminological Views], 2007, no. 4, pp. 117-119.

2. Eliseev A.M., Abdrashitov V.M. Fenomen IGIL: puti resheniya problemy [ISIL Phenomenon: Ways to Solve the Problem]. Teoreticheskie $i$ prakticheskie aspekty razvitiya nauchnoy mysli $v$ sovremennom mire: sbornik statey mezhdunarodnoy nauchno-prakticheskoy konferentsii ["Theoretical and Practical Aspects of the Development of Scientific Thought in the Modern World". Collection of Articles of the International Scientific and Practical Conference]. Ekaterinburg, 2015, pp. 224-225.

3. Informatsionnoe pismo Generalnoy prokuratury RF ot 10.10.2016 № 27-29-2016/Ip10378-16. Ob osobennostyakh nadzornoy deyatelnosti po presecheniyu rasprostraneniya materialov ekstremistskogo kharaktera v seti «Internet» v pervom polugodii 2016 g. [Information Letter of the Prosecutor General's Office of the Russian Federation of 10.10.2016 no. 27-29-2016/Ip10378-16. On the Peculiarities of Supervisory Activities to Suppress the Distribution of Extremist Materials on the Internet in the First Half of 2016]. Access from Reference Legal System "KonsultantPlus".

4. Kahhorov D.G. Sovremennye problemy borby s religioznym ekstremizmom na postsovetskom prostranstve (na primere Respubliki Tadzhikistan) [Contemporary Problems of Combating Religious Extremism in the Post-Soviet Space (on the Example of the Republic of Tajikistan)]. Problemy protivodeystviya prestupleniyam ekstremistskoy napravlennosti na sovremennom etape razvitiya Rossii: materialy regionalnogo kruglogo stola (Volgograd, 31 maya 2019 g.) [Problems of Combating Extremist Crimes at the Current Stage of Russia's Development. Materials of the Regional Round Table (Volgograd, May 31, 2019)]. Volgograd, Volgograd Institute of Management - branch of RANKHiGS, 2019, pp. 28-33.

5. Merkur'ev V.M. Zadachi prokuratury Rossiyskoy Federatsii po protivodeystviyu ekstremizmu i terrorizmu v kontekste obespecheniya natsionalnoy bezopasnosti [Tasks of the Prosecutor's Office of the Russian Federation to Counter Extremism and Terrorism in the Context of National Security]. Vestnik Akademii Generalnoy prokuratury Rossiyskoy Federatsii [Journal of the Academy of the Prosecutor General's Office of the Russian Federation], 2016, no. 3, pp. 44-53.

6. Poslanie Prezidenta Rossiyskoy Federatsii Federalnomu Sobraniyu ot 15.01.2020 [Address of the 
President of the Russian Federation to the Federal Assembly Dated 15.01.2020]. Access from Reference Legal System "KonsultantPlus".

7. Prikaz Generalnyy prokuror Rossiyskoy Federatsii ot 10.11.2017 g. "Polozhenie ob upravlenii po nadzoru za ispolneniem zakonov o federalnoy bezopasnosti, mezhnacionalnykh otnosheniyakh, protivodeystvii ekstremizmu i terrorizmu» [Order Prosecutor General of the Russian Federation of 10.11.2017. "Provision on Management on Supervision of Performance of Laws on Federal Safety, International Relations, Counteraction to Extremism and Terrorism"]. URL: https://genproc.gov.ru/documents/orders/ document-14312 (accessed 22 February 2020).

8. Svodnyy otchet Generalnoy prokuratury $R F$ po forme ON za yanvar-dekabr $2016 \mathrm{~g}$. «Nadzor za ispolneniem zakonov, soblyudeniem prav i svobod cheloveka i grazhdanina» [Consolidated Report of the Prosecutor General's Office of the Russian
Federation on the form of the ON for January December 2016 "Supervision of the Implementation of Laws, Observance of Human and Civil Rights and Freedoms"]. URL: https://genproc.gov.ru/anticor/doks (accessed 22 February 2020).

9. Spravka o sostoyanii zakonnosti v sfere mezhnatsionalnykh otnosheniy $i$ protivodeystvii ekstremistskoy deyatelnosti v 2016 g. Generalnoy prokuratury $R F$ [Certificate on the State of Legality in the Sphere of Inter-Ethnic Relations and Combating Extremist Activities in 2016 of the Prosecutor General's Office of the Russian Federation]. URL: https:// genproc.gov.ru/stat/data/?PAGEN_1=3 (accessed 22 February 2020).

10. Davletgildeev R.Sh., Kostin S.A. Organization for Security and Cooperation in Europe: Analysis of State, Prospects and Opportunities for Cooperation Against the Illegal Migration and Terrorism. HELIX, 2018, vol. 8, no. 6, pp. 4623-4624.

\section{Information About the Authors}

Davlatali G. Kakhkhorov, Senior Lecturer, Department of Criminal Procedure and Criminalistics, Volgograd State University, Prosp. Universitetsky, 100, 400062 Volgograd, Russian Federation, kahhorov@volsu.ru, https://orcid.org/0000-0003-1622-9339

Vagip M. Abdrashitov, Doctor of Sciences (Jurisprudence), Professor, Department of Theory and History of Law and State, Volgograd State University, Prosp. Universitetsky, 100, 400062 Volgograd, Russian Federation, abdrashitov@volsu.ru, https://orcid.org/0000-0003-4058-0428

Shavkat H. Machidzoda, Assistant Prosecutor of Kanibadam, Kanibadam Prosecutor's Office, Ismoili Somoni St., 382, 735900 Kanibadam, Republic of Tajikistan, m.shavkat_1991@mail.ru, https://orcid.org/0000-0001-7816-0432

\section{Информация об авторах}

Давлатали Гаффорович Каххоров, старший преподаватель кафедры уголовного процесса и криминалистики, Волгоградский государственный университет, просп. Университетский, 100, 400062 г. Волгоград, Российская Федерация, kahhorov@volsu.ru, https://orcid.org/0000-0003-1622-9339

Вагип Мнирович Абдрашитов, доктор юридических наук, профессор кафедры теории и истории права и государства, Волгоградский государственный университет, просп. Университетский, 100, 400062 г. Волгоград, Российская Федерация, abdrashitov@volsu.ru, https://orcid.org/0000-0003-4058-0428

Шавкат Хабибулло Мачидзода, помощник прокурора города Канибадам, Прокуратура города Канибадама, ул. Исмоили Сомони, 382, 735900 г. Канибадам, Республика Таджикистан, m.shavkat_1991@mail.ru, https://orcid.org/0000-0001-7816-0432 